\title{
(MULTI)LETRAMENTO(S) E IDENTIDADE: ANÁLISE DE CARTAZES PRODUZIDOS NO ÂMBITO DO GRUPO DE HIP-HOP “A REDE” EM OURO PRETO - MG
}

Hércules Tolêdo Corrêa (Universidade Federal de Ouro Preto)

\section{RESUMO}

Este artigo tem por objetivo apresentar uma análise linguístico-discursiva de cartazes multimodais produzidos no âmbito do grupo de hip-hop "A rede", de Ouro Preto MG. Apoiamo-nos nos estudos sobre os letramentos (os chamados Novos Letramentos e os multiletramentos), principalmente no âmbito dos estudos linguísticos e da educação. A análise partiu de uma coleta de dados realizada por meio da observação participante e entrevistas, de abordagem etnográfica. Os resultados demonstram que os participantes do grupo "A rede" produzem textos multimodais eficientes em seus objetivos e que demarcam seus lugares sociais com a ressignificação de suas identidades. Essas práticas sociais multiletradas espontâneas e engajadas não são, muitas vezes, reconhecidas e valorizadas pela escola.

PALAVRAS-CHAVE: Multiletramentos; multimodalidade; identidades; letramentos de reexistência.

Um pouco antes da virada do milênio, quando se fortaleciam no Brasil as publicações e pesquisas sobre os letramentos, um artigo de Monteiro (1999) procurava discutir em que medida os trabalhos realizados em Linguística Aplicada (LA) poderiam auxiliar no desenvolvimento do processo de letramento (ainda não estava bastante difundido no país o uso do termo no plural) e quais as perspectivas para pesquisas futuras na área. Ao fazer levantamento sobre o objetivo e funções da LA, Monteiro retoma o artigo de Beaugrande (1992), 
intitulado $O$ dilema da linguística teórica, no qual o estudioso europeu apresenta questões epistemológicas sobre as pesquisas em linguística e apresenta as condições e tarefas da LA. Dentre essas tarefas, caberia à Linguística Aplicada uma descrição das estratégias discursivas utilizadas por grupos específicos de falantes, estabelecendo, para tanto, novos procedimentos de medida, de forma que os parâmetros permitissem a distinção dos diferentes estágios de desenvolvimento em que esses falantes ou grupos se encontram em relação às habilidades linguísticas. Monteiro retoma ainda a discussão da natureza interdisciplinar da linguística textual, citando o pesquisador brasileiro Moita-Lopes (1996), para quem a LA é uma ciência social, já que seu foco está nos problemas dos usos da linguagem enfrentados pelos participantes do discurso no contexto social; isto é, usuários da linguagem (leitores, produtores de textos, falantes, ouvintes) no meio escolar e fora dele (por exemplo, em empresas, nos grupos sociais etc.). A linguística aplicada constitui uma ciência que focaliza a linguagem do ponto de vista processual. Coloca-se foco na linguagem da perspectiva do uso/usuário no processo da interação linguística escrita e oral. Portanto, a teoria linguística que interessa ao linguista aplicado deve dar conta dos tipos de competências e procedimentos de interpretação e produção linguística que definem o ato da interação linguística (p. 22-23). Da mesma forma que a LA tem natureza interdisciplinar, também os estudos dos letramentos (como também os da alfabetização) têm chamado a atenção não só de pesquisadores da área da Educação e da Linguagem, como também da Antropologia, da Sociologia, da Psicologia, dentre outras áreas.

A partir de uma mudança de perspectiva dos estudos anglosaxões sobre literacy, deslocando-se do cognitivo para o social, surgem os chamados New Literacy Studies ou Novos Estudos do Letramento. Com a emergência dos estudos sobre os diferentes campos do letramento, o uso da palavra no plural, letramentos, torna-se bastante comum, não sem uma certa tensão por parte dos estudiosos sobre o assunto, a fim de designar diferentes formas e tipos de letramento, o escolar, o acadêmico, o literário, dentre outros. Já o termo multiletramentos ganha repercussão a partir da publicação de livro organizado por Cope \& Kalantzis (1996-2000), quando o grupo de estudiosos reunidos na cidade norte-americana de Nova Londres propõem uma Pedagogia dos Multiletramentos, a fim de refletir sobre a formação de sujeitos com competências suficientes para lidar com 
as diferentes linguagens num ambiente multicultural (COPE E KALANTZIS, 2000 e ROJO e MOURA, 2012).

Partindo-se dessa discussão do escopo da linguística aplicada e embasados nos estudos sobre os multiletramentos, apresentamos aqui um recorte de um estudo sobre os processos de (multi)letramento(s) de um grupo específico da cidade de Ouro Preto, em Minas Gerais. Este artigo se propõe a analisar algumas produções multimodais do grupo de hip-hop "A rede". Este trabalho insere-se numa pesquisa mais ampla, desenvolvida sob minha orientação no Programa de PósGraduação em Educação Mestrado da Universidade Federal de Ouro Preto, intitulada Letramentos em espaços não escolares: o movimento hip-hop e o grupo "A rede", de Ouro Preto, realizado por Fabiana Correia Justo, a quem registro meu especial agradecimento pela coleta dos dados aqui apresentados e analisados.

\section{0 grupo "A rede" e a produção escrita e multimodal}

Identificamos hoje em dia, nos centros urbanos de cidades de pequeno, médio e grande porte, comunidades que se organizam a partir de seus interesses específicos, como é o caso do grupo "A rede", que se constituiu em um bairro periférico da cidade de Ouro Preto, em torno da chamada cultura hip-hop. No âmbito desse grupo, acontecem diferentes práticas de produção de textos verbais e não verbais, que circulam na comunidade e no seu entorno. Dentre esses textos produzidos, temos os cartazes de divulgação dos eventos promovidos pelo grupo e os informativos sobre os trabalhos. Pretendese, aqui, apresentar uma análise de alguns cartazes de divulgação de eventos promovidos pelo grupo.

A coleta de dados foi realizada por meio de observação participante e entrevistas semi-estruturadas com membros do grupo, além da recolha e organização de produtos textuais impressos e digitais produzidos no âmbito do grupo "A rede", num trabalho de abordagem etnográfica.

Entendidos, em poucas palavras, como práticas sociais de leitura e de escrita, os letramentos estão por toda parte, em diferentes âmbitos, tanto escolares como não escolares. Aqui, procuramos fazer uma reflexão sobre práticas de letramentos não escolares, muitas vezes desconsideradas e desprezadas pela instituição escolar e seus agentes, com o intuito de refletir sobre como essas práticas podem ser 
incorporadas pela escola, promovendo, assim, uma maior integração comunidade-escola, e como essas práticas se constituem também como forma de afirmação e constituição de identidades individuais e de grupos.

As práticas de letramentos desenvolvidas no âmbito do grupo "A rede" caracterizam-se pelo que o pesquisador Brian Street denomina de letramentos locais (STREET, 2003 e 2014). Façamos aqui um parêntese para tratar desses letramentos locais e sua relação com a universidade e com a escola.

É papel da universidade pública dar um retorno à sociedade do investimento que nela é feito pelo poder público. Muitos, fora da comunidade acadêmica, não sabem ou não percebem que a universidade atua em três diferentes áreas, que se completam na construção do conhecimento: ensino, pesquisa e extensão. Desses três elementos, apenas o ensino costuma ganhar maior visibilidade e reconhecimento da população, ficando a pesquisa e a extensão em certo obscurantismo. De forma semelhante, no âmbito da própria universidade, também a pesquisa e a extensão também ficam muitas vezes relegadas a segundo e terceiro planos. Quando surgiu a possibilidade de orientarmos o projeto de pesquisa proposto por Justo (2015), de reconhecimento, estudo e valorização das práticas de letramentos surgidas e desenvolvidas no âmbito do grupo "A rede", com sede em um dos morros da periferia de Ouro Preto, aderimo-nos rapidamente à proposta, mesmo sem ter grande inserção na área dos estudos étnicorraciais.

Estudos de sociólogos mostram que o hip-hop surge nos Estados Unidos da América, por volta dos anos 1970, e se espalham pelo mundo ocidental. No Brasil, desenvolve-se principalmente a partir dos anos 1980. A histórica cidade de Ouro Preto, incrustada entre as montanhas mineiras, não ficou fora desse movimento. Com uma população predominantemente negra, o movimento hip-hop em Ouro Preto ganha força com o grupo "A rede".

Que cultura é essa produzida pelos jovens negros da periferia de Ouro Preto? Que práticas de leitura e escrita têm esses sujeitos? Como eles se constituem como sujeitos, em suas identidades, por meio da linguagem? Essas são perguntas que tentamos responder na pesquisa mais ampla e que tentamos, de alguma forma, resumir no âmbito deste artigo, que trata apenas de uma pequena amostra dos materiais coletados.

Muito se discute, hoje em dia, sobre a globalização e seus efei- 
tos. No interior dessa discussão, surge uma outra, que é sobre aquilo que seria o contrário do "global", o "local", o específico, o particular. Dessa forma, queremos entender como esta cultura "local" se insere num contexto mais geral, o "global". Quais são as práticas desses sujeitos que estão relacionadas à sua própria identidade como grupo e quais são aquelas que são mais gerais, mais globais?

Antes de analisarmos alguns cartazes específicos produzidos pelo grupo "A rede" é preciso explicitar o que entendemos por texto, já que trataremos esses produtos multimodais que são os cartazes como textos. Em sentido mais estrito, o texto circunscreve-se à linguagem verbal, em sua modalidade escrita, mas também na sua modalidade oral. Em sentido mais amplo, com o advento de áreas como a semiótica e a semiologia, o conceito de texto passou a abarcar também outros sistemas de significação. Assim, imagens também são consideradas textos. Uma pintura, um filme, uma escultura, dentre outros objetos semióticos, são considerados texto em sentido amplo.

No âmbito da Linguística Textual (LT), Costa Val afirma que "um texto é uma ocorrência linguística, escrita ou falada de qualquer extensão, dotada de unidade sociomunicativa, semântica e formal" (1991). Todo texto é situado historicamente, o que nos leva a afirmar que o estudo do texto não se limita à análise das estruturas linguísticas nele presentes, mas também de seu contexto histórico de produção, circulação e recepção. Segundo o linguista Beaugrande, citado na introdução deste artigo, "o texto é um evento comunicativo em que se convergem ações linguísticas, sociais e cognitivas" (1997), o que nos leva à conclusão de que o texto é uma "unidade de sentido", conforme sintetiza Marcuschi (2005). A concepção de Beaugrand pressupõe que um texto vai além de sua estrutura e deve ser considerado num nível superior ao morfossintático. Diferentes autores apresentaram o que se convencionou chamar de "fatores de textualidade", que são apresentados por Beaugrande e Dressler (1981) e retomados por Costa Val (1991, 2000): coesão e coerência (relacionados ao material conceitual e material do texto), intencionalidade, informatividade, aceitabilidade, situacionalidade, intertextualidade (relacionados a fatores pragmáticos do processo sociocomunicativo).

Do ponto de vista da teoria semiótica, trabalhada, no Brasil, por pesquisadores como Fiorin (1995), há textos verbais e não verbais, e qualquer tipo de texto é formado por um "plano de conteúdo" e um "plano de expressão". No plano de conteúdo, tanto para os tex- 
tos verbais quanto não verbais percebem-se as estruturas da significação organizadas em um "percurso gerativo de sentido" (os significados, tal como proposto por SAUSSURE, 1916). No plano de expressão, enquanto nos textos verbais temos os significantes (na acepção proposta por SAUSSURE, 1916) nos textos não verbais, como a pintura, temos a cor, a espacialidade, a luz e a forma. Na perspectiva da semiótica social, a multimodalidade é entendida como a co-presença de várias formas de linguagem em interação na construção dos sentidos da comunicação social. É importante destacar, nessa visão de uso de linguagens, que as diferentes linguagens funcionam em conjunto, sendo que cada uma contribui de acordo com a sua capacidade de fazer significados (KRESS, 2010).

\section{Análise linguístico-discursiva dos cartazes do grupo "A rede"}

Inicialmente, o grupo "A rede" produzia seus cartazes e informativos na base da "tesoura e cola", utilizando revistas usadas, cartolina e canetas variadas. Com a popularização do computador, o grupo começou a usá-lo para fazer a arte de seus cartazes. Atualmente, a arte dos cartazes é feita pelo líder do grupo, o DJ Teko, um rapaz da comunidade, negro, que completou o ensino médio e começou a aprender design gráfico sozinho e posteriormente, em 2010, fez o curso de Iniciação a webdesign pelo SEBRAE - Serviço Brasileiro de Apoio a Micro e Pequenas Empresas (dados coletados por meio de entrevista e auto-declaração). Os cartazes são impressos em gráficas da cidade, em papel A3 ou A4, e afixados em bairros da periferia de Ouro Preto, normalmente onde acontecem as mostras culturais promovidas pelo coletivo. Os cartazes também são veiculados nas redes sociais digitais, como o Facebook, nas páginas dos membros do grupo "A rede".

Elegemos, para apresentar aqui, a análise de três cartazes, selecionados a partir de um elemento visual que se repete: a favela. Conforme foi dito, todos os cartazes apresentam elementos verbais e não verbais, em que diferentes linguagens se mesclam e se sobrepõem, configurando-se como multimodais. Observemos, por exemplo, a figura 1 - Mostra cultural Fala Favela Encontro Hip Hop Dance. 


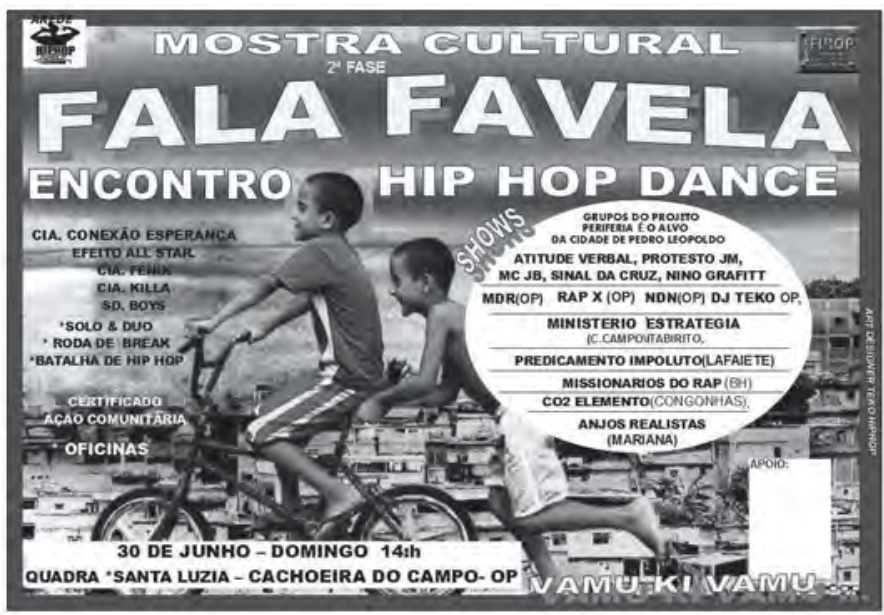

Figura 1

Com predomínio do fundo azul, o cartaz apresenta, como elementos iconográficos, a visão de um aglomerado de casas, em segundo plano, e dois meninos negros brincando de bicicleta. A figura 2 também traz a favela como elemento iconográfico, constituindo todo o fundo do cartaz da Mostra cultural Fala Favela, enquanto a Figura 3, com predomínio da cor preta na parte inferior, traz a favela representada na parte superior, ao fundo, desenhada, e a figura de um rapper, em forma de sombra, no primeiro plano. Compõe também a Figura 2 a imagem de um rapper em sombra numa logomarca no canto inferior esquerdo. Na Figura 3, aparece a imagem de Tiradentes com o triângulo vermelho da bandeira mineira, anunciando a Medalha Periferia, uma possível alternativa da comenda oficial do governo estadual, a tradicional Medalha da Inconfidência, além de outras figuras humanas em forma de sombra, nas extremidades do cartaz.

Ao exibir esses elementos, percebe-se claramente a intenção de marcar o lócus do grupo "A rede” em seus cartazes, qual seja, a periferia e morros da cidade, com as condições de vida dos membros: casas semi-construídas em becos e vielas, sem as completas condições de urbanização típicas do chamado asfalto, as típicas favelas brasileiras. Na Figura 1, os meninos que brincam de bicicleta parecem descontraídos e felizes: o primeiro deles veste bermuda vermelha de listras brancas e camiseta verde e está montado no selim da 
bicicleta. Calça sandálias de borracha. 0 segundo modelo foi fotografado sem camisa e descalço, vestindo apenas um calção amarelo largo. Ambos sorriem, remetendo à descontração e felicidade que se pretende passar com a imagem. Na Figura 2, não há personagens em primeiro plano, diferentemente dos outros dois cartazes. Na Figura 3, o rapper em sombra ocupa o primeiro plano e também representa a descontração do membro que exibe a sua arte de cantor e dançarino.

A identidade do grupo "A rede" é representada iconograficamente, nesses cartazes, por meio da imagem da favela e de seus moradores: crianças felizes que brincam e jovens rappers, que apresentam sua arte. Evidencia-se ainda a marca de identidade do grupo em seus elementos verbais (uso dos estrangeirismos, desvios da norma culta, influência da linguagem dos meio digitais) conforme se demonstra em seguida.

0 texto da Figura 1 pode ser dividido em três partes, na sua horizontal. Na primeira parte, temos evidenciado o nome do evento em letras brancas e amarelas, sendo que a expressão "Fala favela" aparece em destaque, na cor amarela. Nota-se, ainda, a presença de duas logomarcas, representativas dos promotores do evento, cada uma delas em um dos cantos superiores do cartaz. Na segunda parte, a maior delas, observa-se, do lado esquerdo, nomes de participantes do evento. Do lado direito encontram-se os títulos dos artistas e shows que farão parte da mostra. Por fim, na última parte, e a menor delas, registra-se a data, o horário e o local do evento.

A Figura 2 traz um texto que pode ser dividido em três partes também, mas com tamanhos diferentes da Figura 1. Na Figura 2 o nome do evento está evidenciado na primeira parte, em letras amarelas, com tamanho da fonte bem maior que os demais textos. Na parte do meio, há informações sobre a data e o local da mostra. Na parte inferior, figuram as atrações do evento. Ressalta-se nesta parte as logomarcas do FIROP - Fórum de Igualdade Racial de Ouro Preto e do Hiphop e, ainda, a chamada: Atenção galera!!! Venha de aba reta 


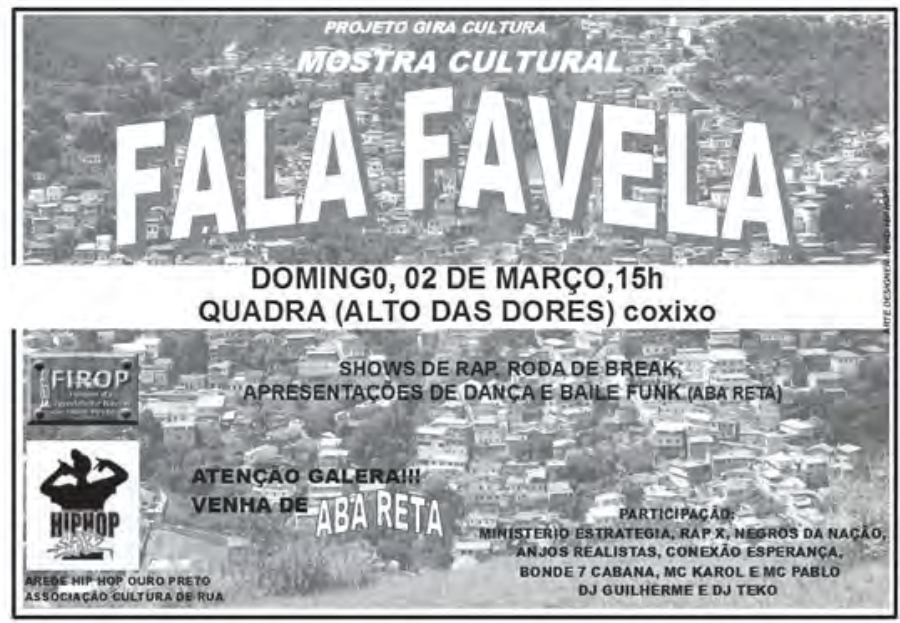

Figura 2

A Figura 3 também traz um texto que pode ser dividido em três partes. Na parte superior, o título do evento, em que há destaque para três subpartes: a) Cultura é favela, favela é cultura; b) Mostra cultural; c) Fala Favela. Na parte do meio, informações sobre local e data do evento e, por fim, na parte inferior, as atrações do evento e, por último, entre aspas, a expressão “A nossa Inconfidência”, que dialoga diretamente com a imagem conhecida de Tiradentes - construída pela História oficial e divulgada amplamente pela mídia - da parte intermediária do cartaz.

0 grupo "A rede" apresenta uma maneira alternativa de comemorar a Inconfidência Mineira, no 21 de abril. 0 coletivo critica o fato de a Medalha da Inconfidência, outorgada pelo governo estadual, ser usada para homenagear pessoas que não são de Ouro Preto nem têm ligação direta com a cidade e com sua população. Há também uma crítica ao fato de que nesta data os moradores de Ouro Preto não podem circular no centro histórico, sendo alijados de seu próprio espaço. 


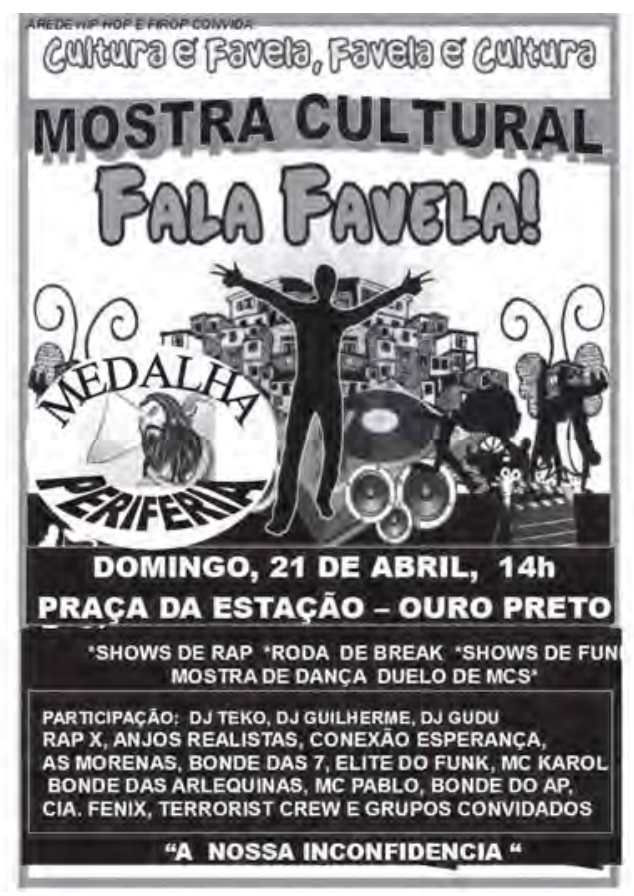

Figura 3

Percebe-se que os cartazes foram produzidos com muito cuidado: há a preocupação com o equilíbrio entre o verbal e o não verbal; observa-se a preocupação em apresentar as fotografias em primeiro e segundo planos, com a representação do ambiente e de seus personagens. Na linguagem verbal, observamos a convivência da norma culta com registros coloquiais e populares, com influência do meio digital (ressalte-se, por exemplo, o registro da expressão "vamu ki vamu” - percebe-se que o desvio da norma culta não ocorre por falta de conhecimento dessa norma, mas pela intenção explícita de reproduzir uma expressão usada pelos membros do grupo, uma espécie de gíria, registrando-a com o desvio do padrão do português). Ressaltase também a convivência harmoniosa de termos vernáculos e estrangeirismos (hip hop, all star, boys, break, shows, rap, funk, MC, $D J$, dentre outras).

Destaca-se ainda o nome do evento: Fala favela. 0 uso do imperativo no registro popular (fala, em lugar de fale) e a ausência da 
vírgula para separar o vocativo (favela) parece evidenciar duas coisas: 1) o uso de "fala" representa muito mais os usos linguísticos orais locais; 2) a ausência da vírgula deixa em suspenso a possibilidade de análise de "favela" como vocativo e viabiliza sua análise como o sujeito do enunciado (a favela fala, é a hora de a favela falar...) Destaca-se também a repetição dos sons [f] - fricativa labiodental desvozeada e [v] - fricativa labiodental vozeada (CRISTÓFARO-SILVA E YEHIA, 2011), promovendo os efeitos fonético e poético da aliteração.

Os cartazes analisados cumprem suas funções enquanto gênero textual e discursivo: servem para divulgar o evento, têm os mesmos elementos de outros cartazes produzidos em diferentes contextos (o que se anuncia, quando e onde acontecerá, quem promoverá). Podem ser considerados textos autênticos, tanto do ponto de vista da Linguística Textual quanto da Semiótica. Têm coerência, ou melhor, os leitores normalmente não têm dificuldade de compreendê-los. Há grande possibilidade de comunicação com os receptores, que podem identificar, em cada um dos produtos, uma "unidade de sentido", um todo compreensível (material conceitual, como apontado anteriormente), que cumpre sua função comunicativa. Também têm coesão, que se percebe por meio das relações que se estabelecem entre as diferentes partes do texto verbal (material textual, também conforme apontado anteriormente).

Com relação aos fatores pragmáticos do processo sociocomunicativo desses textos híbridos e multimodais, que são os cartazes, podemos perceber que estes cumprem os demais pré-requisitos da textualidade, quais sejam: a) a intencionalidade, uma vez que cumprem suas funções de cartazes, textos do domínio publicitário que têm por objetivo persuadir os receptores; b) a informatividade, já que trazem informações novas relevantes para os receptores, como local e data dos eventos, atrações, nomes de promotores; c) a aceitabilidade, uma vez que se configuram como objetos informativos com características semelhantes a de outros objetos do mesmo gênero e que, portanto, não soam estranhas para os receptores; d) a situacionalidade, configurada pelo contexto em que são produzidos esses textos, o grupo comunitário e suas práticas artísticas e letradas; e por fim, e) a intertextualidade, que pode ser avaliada tanto em termos do diálogo estabelecido entre esses três cartazes aqui analisados e a recorrência, por exemplo, do ícone da favela, ou as relações estabelecidas com outros cartazes e informativos do grupo, não ana- 
lisados aqui, e cartazes produzidos também por outros grupos com suas semelhanças e diferenças.

\section{Apontamentos finais}

A partir dos dados aqui apresentados, podemos concluir que a produção e a circulação de cartazes como estes mostra que existem, de fato, práticas de (multi)letramento(s) efetivas no contexto do grupo cultural "A rede", as quais merecem a atenção de estudiosos sobre 0 assunto.

Se os membros desse grupo utilizam práticas tão sofisticadas de (multi)letramento(s) para divulgar sua cultura (vale observar a quantidade de grupos artísticos que se apresenta no evento, bem como a promoção das diferentes oficinas), identificada na breve análise desses cartazes (não estamos, aqui, analisando as demais práticas artístico-culturais do grupo), acreditamos que estudiosos dos letramentos escolares e acadêmicos precisam conhecer (re-conhecer também) e valorizar essas práticas, a fim de repensar e ressignificar as práticas de letramentos consideradas legítimas nas instituições em que atuam.

Acreditamos que reconhecendo o modo como esses sujeitos se apropriam de práticas de leitura e escrita em suas atividades cotidianas, responsáveis por políticas públicas de educação, autores de material didático e, principalmente, professores de língua portuguesa e das demais disciplinas escolares poderão compreender o sucesso alcançado por esses jovens nessas práticas, o que pode ajudar na reflexão sobre políticas de letramentos escolares que realmente possam motivar os educandos, nas quais estes sejam agentes proficientes na produção de textos na escola, assim como o são nos textos produzidos em outras esferas sociais. Trata-se, portanto, muito mais do que os chamados letramentos de resistência, letramentos de reexistência, uma vez que possibilitam a esses jovens redimensionar suas identidades, ressignificando papéis e lugares sociais atribuídos por uma sociedade marcada por desigualdades raciais e sociais (SOUZA, 2011 e JUSTO, 2015). 
This article aims to present a linguistic-discursive analysis of multimodal posters produced in the hip-hop group "A rede", of Ouro Preto - MG . We support in New Literacy Studies and the pedagogy of multiliteracies, especially within the linguistic studies and education. The analysis started from a data collection conducted through participant observation and interviews, ethnographic approach. The results showed that participants in the group "A rede" produce efficient multimodal texts on your goals and demarcate their social places with the redefinition of their identities. These spontaneous and engaged multiliteracy social practices are not often recognized and valued by the school.

KEYWORDS: Multiliteracies; multimodality; identity; literacies of re-existence.

\section{REFERÊNCIAS}

BEAUGRANDE, Robert de; DRESSLER, Wolfgang U. Introduction to text linguistics. London; New York: Longman, 1981.

BEAUGRANDE, Robert de. New foundations for a science of text and discourse: cognition, communication and freedom of access to knowledge and society. Norwood, New Jersey: Ablex Publishing Corporation, 1997.

COPE, Bill.; KALANTZIS, Mary. Multiliteracies: literacy learning and the design of social futures. London; New York: Routledge, 2000.

COSTA VAL, Maria da Graça. Redação e textualidade. São Paulo: Martins Fontes, 1991.

COSTA VAL, M da G. Repensando a textualidade. In: AZERED0, J. C (org.) Língua portuguesa em Debate: conhecimento e ensino. Petrópolis: Vozes, 2000.

CRISTÓFARO-SILVA, Thaïs; YEHIA, Hani Camille. Sonoridade em Artes, Saúde e Tecnologia. Revista Docência do Ensino Superior, v. 1, p. 1-13, 2011.

FIORIN, José Luiz. A noção de texto na semiótica. Revista Organon, Porto Alegre, v. 9, n. 23, 1995. 
KRESS, Gunther. Multimodality: A social semiotic approach to contemporary communication. London: Routledge, 2010.

JUSTO, Fabiana Correia. Letramentos em espaços não escolares: o movimento hip-hop e o grupo "A rede", de Ouro Preto. Programa de Pós-Graduação Mestrado em Educação. Mariana: UFOP, 2015.

MARCUSCHI, L. A. Produção textual, análise de gênero e compreensão. São Paulo: Parábola Editorial, 2008.

MONTEIR0, Rosemeire Selma. A linguística aplicada e o processo de letramento. Revista de Letras. Ceará, Fortaleza, v. 21, n. 1-2, jan.-dez. 1999. ROJO, Roxane e MOURA, Eduardo (Orgs.) Multiletramentos na escola. São Paulo: Parábola, 2012.

SAUSSURE, Ferdinand; BALLY, Charles; SECHEHAYE, Albert; RIEDLINGER, Albert. Curso de linguística geral. 11a ed. São Paulo: Cultrix, [1984?] Original de 1916

SOUZA, Ana Lúcia Silva. Letramentos de reexistência: poesia, grafite, música, dança, hip-hop. São Paulo: Parábola, 201

STREET, Brian. Letramentos sociais. Abordagens críticas do letramento no desenvolvimento, na etnografia e na educação. São Paulo: Parábola Editorial, 2014.

STREET, What's "new" in New Literacy Studies? Critical approaches to literacy in theory and practice. Current Issues in Comparative Education, Columbia University, Vol.5 (2), 2003.

Recebido em 29 de maio de 2015

Aprovado em 03 de junho de 2015 